\title{
Field Test of Optical and Electrical Fire Detectors in Simulated Fire Scenes in a Cable Tunnel
}

\author{
Dian FAN ${ }^{1 *}$, Hongjun DING ${ }^{1,2}$, Dorothy Y. WANG ${ }^{3}$, and Desheng JIANG ${ }^{1}$ \\ ${ }^{1}$ National Engineering Laboratory for Fiber Optic Sensing Technology, Wuhan University of Technology, Wuhan, \\ 430070, China \\ ${ }^{2}$ Shenyang Fire Research Institute, Shenyang, 110034, China \\ ${ }^{3}$ Center for Photonics Technology, Bradley Department of Electrical and Computer Engineering, Virginia Polytechnic \\ Institute and State University, Blacksburg, VA 24061, USA \\ *Corresponding author: Dian FAN_Ｅ-mail: fandian@whut.edu.cn
}

\begin{abstract}
This paper presents the testing results of three types of fire detectors: electrical heat sensing cable, optical fiber Raman temperature sensing detector, and optical fiber Bragg grating (FBG) temperature sensing detector, in two simulated fire scenes in a cable tunnel. In the small-scale fire with limited thermal radiation and no flame, the fire alarm only comes from the heat sensors which directly contact with the heat source. In the large-scale fire with about $5{ }^{\circ} \mathrm{C} / \mathrm{min}$ temperature rising speed within a 3-m span, the fire alarm response time of the fiber Raman sensor and FBG sensors was about 30 seconds. The test results can be further used for formulating regulation for early fire detection in cable tunnels.
\end{abstract}

Keywords: Fire simulation, fire detector, cable tunnel, response time

Citation: Dian FAN, Hongjun DING, Dorothy Y. WANG, and Desheng JIANG, "Field Test of Optical and Electrical Fire Detectors in Simulated Fire Scenes in a Cable Tunnel," Photonic Sensors, 2014, 4(2): 156-161.

\section{Introduction}

Along with the increasing importance of fire alarms in the modern industries and infrastructures, the investigation into fire detectors is becoming more desirable. In recent years, with the rapid progress of the optical fiber sensing technology [1], many optical fiber fire sensors have been developed and become principal techniques in various applications because of their outstanding performances and unique advantages. For example, in cable tunnels, fiber Raman [2] and fiber Bragg grating (FBG) [3] temperature sensors have attracted much attention for fire detection because of their distributed measurement capability, high sensitivity, and fast response. However, the existing standards [4-7] have not been updated due to the lack of investigation into the viability and adaptability of these new sensing techniques in field conditions. Therefore, further research is needed in the following major tasks:

(1) Installation. For large-scale fires, the detector can be installed on the top of the tunnel as suggested by the highway tunnel fire safety standards. But there is no such reference for small-scale fire caused by overheating of the cables. Some manufacturers proposed the sine-wave laying of the fire detectors along the cable. However, its effectiveness, response in time, and location need to be explored and experimentally verified.

Received: 20 December 2013 / Revised version: 12 January 2014

(C) The Author(s) 2014. This article is published with open access at Springerlink.com

DOI: $10.1007 / \mathrm{s} 13320-014-0174-3$

Article type: Regular 
(2) Implementation. There is temperature distribution in the surrounding area in a fire scene, and thus the response time of distributed fire detectors is affected by their spatial distribution. Normally, the detectors with the higher spatial density have the faster response, but also the system cost expensively. Therefore, the optimal selection of the sensor spatial distribution is desired. In addition, since fiber Raman heat detectors require computation of the derivatives in the spatial domain, higher spatial resolution demands more computation amount, resulting in delayed alarm response time. Therefore, it is necessary to thoroughly understand the principles and mechanisms of the new fire detection technologies for the purpose of a better applicability of the standards.

(3) Inspection. Most of the inspection specifications for fire detectors in China use the standards in Europe and the United States for reference. But due to the complexity of the fire scene in cable tunnels, there are many accidents caused by cable overheating, which have no reference for fire simulation specifications. In order to develop effective standards for early fire detection in cable tunnels, it is necessary to analyze the fire causes and characteristics, simulate fire scenes based on practical instances, and evaluate the viability and performance of the fire sensors.

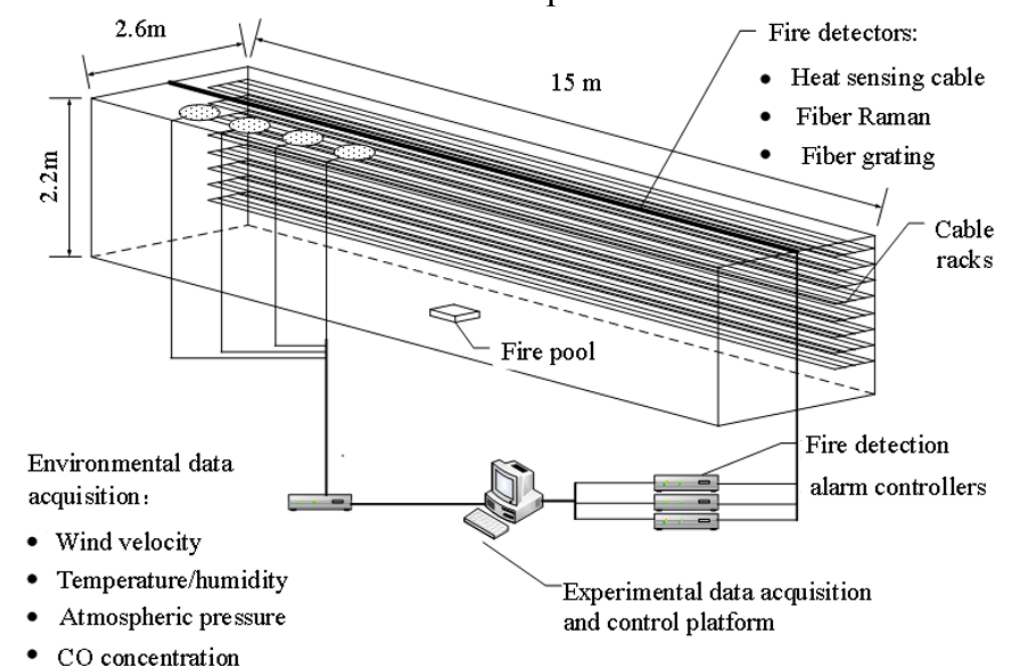

Fig. 1 Schematic of the field test system.

\section{Field test platform}

In this paper, fire scenes of different scales were simulated in the Shenyang Fire Research Institute experiment cable tunnel; the fiber Raman fire sensor and FBG fire sensor were tested and compared with the electrical fire sensor. The experimental system is schematically shown in Fig. 1, which was set in a cable tunnel with cable racks on both sides of the tunnel. A fire pool and a heated silicon carbide rod were used to simulate the large-scale and small-scale fires, respectively. Fire detectors were placed in the cable tunnel and connected to their corresponding alarm controllers. Three types of tested fire detectors were: electrical differential / fixed heat sensing cable, distributed fiber Raman temperature sensing cable, and quasi-distributed FBG temperature sensing cable. Environmental data were also acquired, including the wind velocity, temperature, humidity, atmospheric pressure, and $\mathrm{CO}$ concentration. All the data were collected to the system acquisition and control platform.

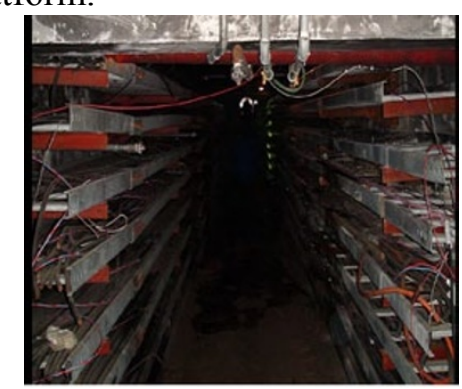

Fig. 2 Photo of the fire simulation experiment cable tunne. 


\subsection{Cable tunnel in the test}

The dimension of the cable tunnel in the test was $2.6 \mathrm{~m}$ width $\times 2.2 \mathrm{~m}$ height $\times 15 \mathrm{~m}$ length. There was an 8-layer cable rack on each side of the tunnel. Each layer had $15 \mathrm{~m}$ length, $0.6 \mathrm{~m}$ width, and $0.2 \mathrm{~m}$ spacing between its neighboring layers, as shown in Fig. 2. There was the natural ventilation in the tunnel. The smoke produced in the test was collected and discharged by the fan system at one end of the cable rack. Power cables and signal cables were set on the cable rack following the layout in an actual project in the tunnel. According to the measured parameters provided by the metallurgy corporation, the general temperature inside the tunnel was between $20{ }^{\circ} \mathrm{C}$ and $29{ }^{\circ} \mathrm{C}$; the humidity was in the range of $49 \%$ to $85 \%$; and the wind velocity was $0.1 \mathrm{~m} / \mathrm{s}-0.4 \mathrm{~m} / \mathrm{s}$ without the exhaust fan.

\subsection{Fire scene simulation}

According to the statistical analysis of fire cases in metallurgy and power industries, the fire can be classified as the small-scale fire and large-scale fire. Small-scale fires are usually caused by the broken cable bitten by rodents' bite or cable ignition by the falling sparks from welding or gas cutting in maintenance. Possible reasons for large-scale fires include cable ignition by high-temperature steel slag or molten steel or oil stain on the ground, and fault oil injection by the oil-immersed electrical equipment. In the test, a small-scale fire simulation device was used, which was composed by a silicon carbide rod, a high-power DC24V power supply, a temperature controller, and an S-platinum-rhodium thermocouple. The working temperature of the silicon-carbide-rod was $800{ }^{\circ} \mathrm{C}$, determined by the measured actual temperature when the cable jacket melted and combusted. The large-scale fire in the test was simulated by alcohol $(90 \%$ ethanol and $10 \%$ methanol) fire in a $330 \mathrm{~mm} \times 330 \mathrm{~mm} \times 50 \mathrm{~mm}$ fire pool by reference to the European standard EN 54-22:2007 (E) [8].

\subsection{Fire detectors}

The fiber Raman temperature sensing system [9] has been developed for real-time distributed temperature measurement. In the system, the optical fiber is not only the light transmission medium but also the sensing element. In Raman scattering, there are Stokes and Anti-Stokes components, whose intensity ratio is a function of temperature.

$$
T=\frac{h \Delta f}{k}\left[\ln \left(\frac{I_{S}}{I_{A S}}\right)+4 \ln \left(\frac{f_{0}+\Delta f}{f_{0}-\Delta f}\right)^{-1}\right]
$$

where $h$ is Planck's constant, $k$ is Boltzmann's constant, $I_{S}$ is the Stokes intensity, $I_{A S}$ is the anti-Stokes intensity, $f_{0}$ is the incident light frequency, $\Delta f$ is the Raman frequency shift, $f_{0}-\Delta f$ is the Stokes frequency, and $f_{0}+\Delta f$ is the anti-Stokes frequency. Short pulses were launched into the sensing fiber, and their backscattered Raman signals with local temperature information were collected distributedly along the fiber. After signal demodulation, the temperature distribution profile along the sensing fiber could be obtained.

An FBG [10] is an optical fiber device formed by the periodic change in the refractive index in the fiber core. This periodic refractive index perturbation enables modal coupling between the forward-propagation core mode and the backwardpropagation core mode at a specific wavelength, called the Bragg wavelength. The Bragg wavelength depends on the spatial period $\Lambda$ and amplitude of the refractive index modulation, which follows the first-phase approximate matching condition of the mode coupling theory:

$$
\lambda_{B}=2 n_{\text {eff }} \Lambda
$$

where $\lambda_{B}$ is grating's Bragg wavelength, and $n_{\text {eff }}$ is the effective refractive index of the grating in the fiber core. Temperature can change the Bragg wavelength due to the thermo-optic (dominant) and thermal expansion effect. Hence, we have

$$
\Delta \lambda_{B}=2\left(n_{\mathrm{eff}} \frac{\partial \Lambda}{\partial T}+\Lambda \frac{\partial n_{\mathrm{eff}}}{\partial T}\right) \Delta T .
$$


Accordingly, temperature information can be determined by monitoring the Bragg wavelength shift in the reflection spectrum. The typical FBG fabrication method is based on the ultraviolet (UV) irradiation through a phase mask. There are several FBG multiplexing techniques including timedivision, frequency-division, and wavelengthdivision multiplexing. In this project, wavelengthdivision multiplexing was used to multiplex 5 FBG sensors (interval $3 \mathrm{~m}$ ) in one fiber.

The temperature sensing cable [11] is divided into digital type and analog type. The digital type is a "switch" type cable. When the temperature increases to a certain value, the cable inside will change and produce a short circuit or a thermal collision between the conductors. This "change" is detected by the electrical device that provides the alarm signal. The analog type is a stranded cable of a group of conductor wires, two of which have the polymer cover with the negative temperature coefficient and others of which have the polyvinyl chloride polymer (PVC) material cover. When the temperature changes, the polymer cover's resistance will change. The detection circuit detects the cable impedance, recognizes the temperature change characteristic, and gives the alarm signal.

\section{Results and analysis}

According to the manufacturer's installation instructions and engineering conventions, fire detection cables including electrical fixed temperature sensing cable D1 (D8000A), differential temperature sensing cable D2 (1000A), fiber Raman temperature sensing cable D3 (DTS400), and FBG temperature sensing cable D4 (FBGT112410) were installed on the third, fourth, and fifth layers of the cable rack. They were placed in two forms: sine-wave (S-type) layout in contact with the rack and suspension in a straight line. Thermocouples A1 - A18 were installed on the fourth layer of the rack to monitor the temperature change in the test, as shown in Fig. 3. In the large-scale fire test, detectors
D1 - D4 and thermocouples C1 - C16 (interval 1 m) were straightly hanged on the top of the tunnel. The alarming controller was set $85{ }^{\circ} \mathrm{C}$ as the fixed temperature alarm threshold and $10{ }^{\circ} \mathrm{C} / \mathrm{m}$ in as the difference temperature rising rate alarm threshold.

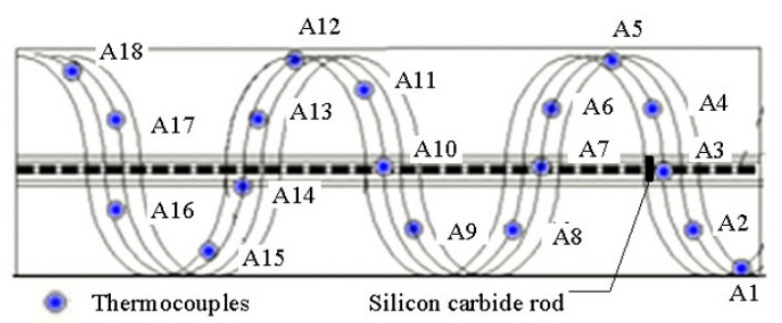

Fig. 3 Scheme diagram of detectors and thermocouples layout in the cable rack.

\subsection{Small-scale fire test}

As required by the small-scale fire simulation model, a silicon carbide rod was heated to $800{ }^{\circ} \mathrm{C}$ and placed on the fourth layer of the cable rack. The fire simulation test was run for two times. Figure 4 shows the temperature change recorded by the thermocouple in one test. Figure 5 shows the fire detectors' response time in the two tests. During the tests, the environmental temperature was $14^{\circ} \mathrm{C}$, the humidity was $39 \%$, the atmospheric pressure was $101.325 \mathrm{kPa}$, the wind speed was $0.14 \mathrm{~m} / \mathrm{s}$, and the $\mathrm{CO}$ concentration exceeded $170 \mathrm{ppm}$ in the fire scene.

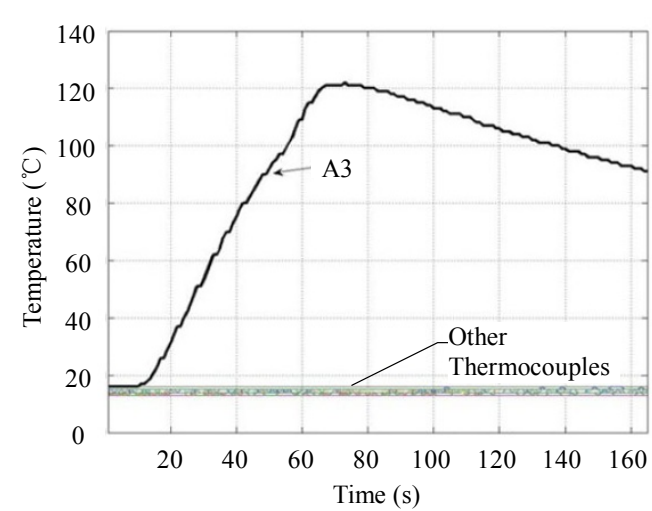

Fig. 4 Temperature variation graph for small-scale fire.

In Fig. 4, the only significant temperature reading change came from thermocouple $\mathrm{A} 3$, which was close to the silicon carbide rod. A3's temperature rose up to above $100{ }^{\circ} \mathrm{C}$ in one minute and then gradually declined after reaching $120^{\circ} \mathrm{C}$. 
Although the temperature of the rod was high, the heat it gave off was small because of its small size (the heating length was less than $10 \mathrm{~cm}$, and the diameter was $1.5 \mathrm{~cm}$ ). Also since there was no continuous heat supply to the rod, its temperature dropped fast; and its functional range was small.

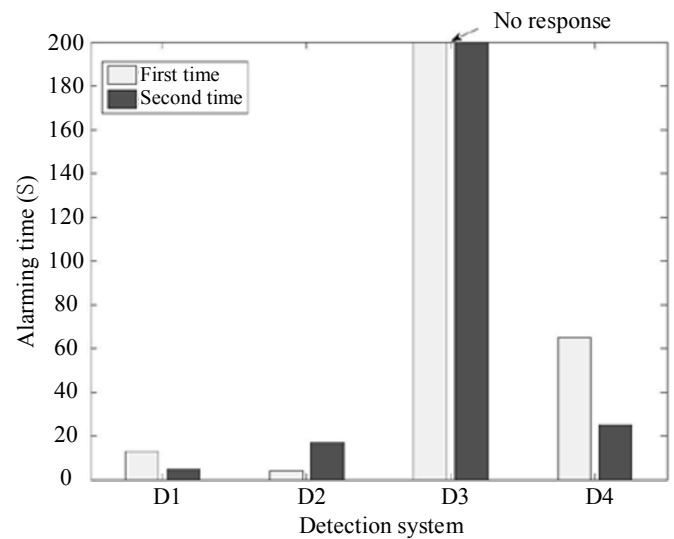

Fig. 5 Comparison bars of detector response time in the beginning of the small-scale fire simulation experiment.

For the small-scale no-flame fire with a small amount of thermal radiation, only the detectors in direct contact with the heat source made fire alarm response. Since the required minimum length for the electrical sensors is several centimeters, they (D1, D2) can give alarm response rapidly when they are in direct contact with the heat source. In the case of the fire Raman temperature sensor, the spatial resolution was generally $1 \mathrm{~m}-3 \mathrm{~m}$, resulting in no response even when the fiber contacted with the heat source. However, since FBGs usually have small sizes (less than $10 \mathrm{~cm}$ ), they (D4) can give alarm response when they are placed close enough to the heat source.

\subsection{Large-scale fire test}

In the large-scale fire scene simulation, an alcohol fire source was placed on the ground in the middle of the cable tunnel. The simulation was run for two times. Figure 6 shows the temperature change recorded by thermocouples in one test; and Fig. 7 shows the response time of the fire detectors in two tests, respectively. During the tests, the environmental temperature was $15^{\circ} \mathrm{C}$, the humidity was $43 \%$, the atmospheric pressure was $101.325 \mathrm{kPa}$, the wind speed was $0.13 \mathrm{~m} / \mathrm{s}$, and the $\mathrm{CO}$ concentration exceeded $110 \mathrm{ppm}$ in the first simulation run.

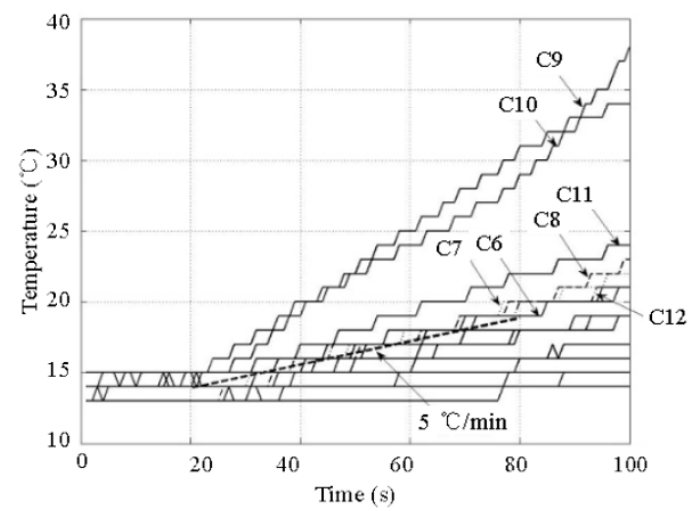

Fig. 6 Temperature variation graph at the beginning of massive fire.

Since the fire alarm response time is a crucial parameter to evaluate the performance of fire detectors, the investigation focuses on the temperature change in the early stage of the large-scale fire. The temperature change in the initial $100 \mathrm{~s}$ recorded by the thermocouples $(\mathrm{C} 1-\mathrm{C} 16)$ is shown in Fig. 6. The ignition was at $t=20 \mathrm{~s}$. Within $60 \mathrm{~s}$ after the ignition, all the thermocouple readings did not exceed $35{ }^{\circ} \mathrm{C}$, which was a reasonable temperature in the normal cable tunnel and was much lower than the typical alarm threshold $\left(85^{\circ} \mathrm{C}\right)$.

Assuming that the alarm threshold of differential temperature sensors is set as the temperature rising rate of $5{ }^{\circ} \mathrm{C} / \mathrm{min}$, indicated by the dash line in Fig. 6 , temperature curves of $\mathrm{C} 6$ to $\mathrm{C} 12$ thermocouples are above the threshold. If the fire detectors' (D2/D3/D4) sensing temperatures were the same as the thermocouples readings, the fire detectors in the range of $\mathrm{C} 6-\mathrm{C} 12$ (6meters) should generate alarm signals in less than 60 seconds. The value of the $6-\mathrm{m}$ distance between two sensors' locations would become an important reference value of standards for the quasi-distributed fire detector including the FBG.

Since the thermal radiation in the large-scale fires is high, fire detectors that were not in direct contact with the fire source could also make fire 
alarm. The temperature around the ignition point changed rapidly, and the temperature rising rate was higher than the difference temperature rising rate alarm threshold $\left(10{ }^{\circ} \mathrm{C} / \mathrm{min}\right)$, so the electrical differential temperature sensor and the optical fiber temperature sensors had the corresponding fast response, while the response time of the fixed temperature sensor was long.

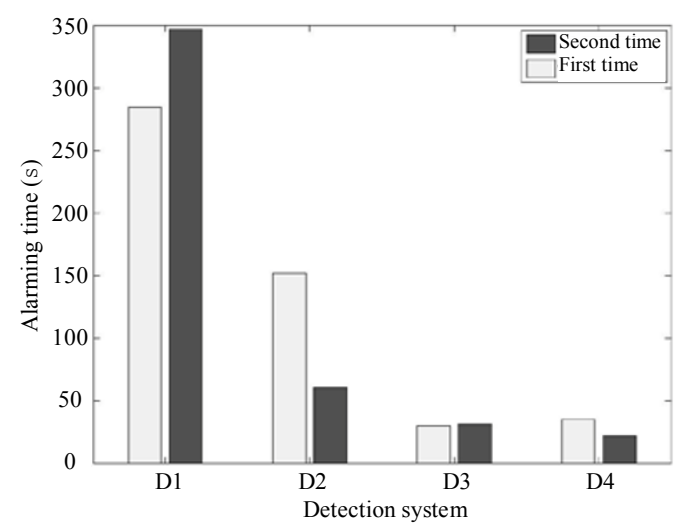

Fig. 7 Comparison bars of detector response time in the massive fire simulation experiment.

\section{Conclusions}

Due to the uncertainty of the fire location in the small-scale fire, there were always blind spots regardless of the installation method of the fire detectors. Because the low rate and small amount of the thermal radiation in the small-scale fire, the detectors which were close enough to the fire location had fast alarm response; while the fiber Raman temperature sensor could not work due to its spatial resolution limit. In the large-scale fire, the fiber Raman temperature sensor and the FBG temperature sensor's alarm response time was about 30 seconds. The temperature within $3 \mathrm{~m}$ of the ignition location was less than $35^{\circ} \mathrm{C}$ in the first $60 \mathrm{~s}$, while the temperature rising rate was more than $5{ }^{\circ} \mathrm{C} / \mathrm{min}$. The field test accomplished in this project evaluated several types of fire detectors in both small-scale and large-scale fire scenes in a cable tunnel, providing the technical support for the formulation and revision of the fire detection standards.

\section{Acknowledgement}

This work was supported by the Chinese National Science Foundation under Grant 51275373 and the Chinese Fundamental Research Funds for the Central University under Grant 2012-IV -019 .

Open Access This article is distributed under the terms of the Creative Commons Attribution License which permits any use, distribution, and reproduction in any medium, provided the original author(s) and source are credited.

\section{References}

[1] E. Udd and B. W. Spillman Jr., Fiber optic sensors: an introduction for engineers and scientists, USA: John Wiley \& Sons, 2011.

[2] H.Ishii, K. Kawamura, T. Ono, H. Megumi, and A. Kikkawa, "A fire detection system using optical fibres for utility tunnels," Fire Safety Journal, 1997, 29(2-3): 87-98.

[3] J. Zhu and D. Fan, "Design of fiber Bragg grating detector in tunnel fire," Journal of Wuhan University of Technology, 2007, 29(4): 107-109 (in Chinese).

[4] GB50414-2007, Code of design on fire protection and prevention for iron \& metallurgy enterprises (in Chinese).

[5] GB50229-2006, Code for design of fire protection for fossil fuel power plants and substations (in Chinese).

[6] GB/T21197-2007, Linear optical fiber temperature sensing fire detector (in Chinese).

[7] GB16280-2005, Linear temperature sensing fire detector (in Chinese).

[8] EN 54-22:2007, Fire detection and fire alarm systems - Part 22: line type heat detectors.

[9] Z. Zhang, S. Jin, and J. Wang, "Recent progress in distributed optical fiber Raman sensors," in Proc. SPIE (Proceedings of 22nd International Conference on Optical Fiber Sensors), Beijing, China, vol. 8421, 2012.

[10] Raman Kashyap, Fiber Bragg gratings. Netherlands: Elsevier Inc., 2010.

[11]Y. Zhang and Q. J. Chen, "Principles, application and future development of conventional tunnel fire detectors," Chinese Journal of Underground Space and Engineering, 2006, 2(2): 311-314 (in Chinese). 